\title{
Abortion Finding
}

National Cancer Institute

\section{Source}

National Cancer Institute. Abortion Finding. NCI Thesaurus. Code C35221.

The unintentional or intentional loss of a pregnancy before 22 weeks gestation. 